\title{
Preferential Replication of HIV-1 in the CD45RO Memory Cell Subset of Primary CD4 Lymphocytes In Vitro
}

\author{
Celsa A. Spina, ${ }^{\star \ddagger}$ Harry E. Prince,,$\|$ and Douglas D. Richman ${ }^{\star \ddagger}$ \\ $*$ The Veterans Affairs Medical Center, San Diego, California 92161; ${ }^{\ddagger}$ Department of Pathology and ${ }^{\S}$ Department of Medicine, University

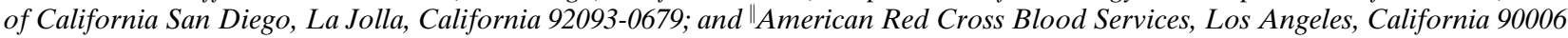

\begin{abstract}
The ability of HIV-1 to establish an infection and replicate to high copy number in CD4 lymphocytes is dependent on both the activation state of the cell and virus-encoded regulatory proteins that modulate viral gene expression. To study these required virus-cell interactions, we have used an in vitro cell model of acute HIV infection of quiescent, primary CD4 lymphocytes and subsequent induction of $T$ cell activation and virus replication by lectin or CD3 receptor cross-linking. Experiments were done to determine if the capacity of HIV to establish infection and complete replication was impacted by the maturational state of the CD4 cell target or the specific signal induction pathway engaged during activation. Primary CD4 cells were FACS ${ }^{\circledR}$-sorted into the major phenotypic subsets representative of memory (CD45RO) and naive (CD45RA) cells. Levels of virus replication were compared between infection with wild-type NL4-3 virus and an isogenic mutant containing a deletion in nef regulatory gene. PHA mitogen stimulation was compared with anti-CD3, with and without anti-CD28 costimulation, for induction of cell proliferation and virus replication. In both infected and uninfected cells, the RA cell subset exhibited significantly greater response to CD3/ CD28 stimulation than did the RO cell subset. In contrast, the majority of virus replication occurred consistently in the RO cell subset. Deletion of HIV nef function caused a severe reduction in viral replication, especially in the RA naive cell subset after CD3 induction. PCR analysis of viral DNA formation, during infection of quiescent cells, demonstrated that the observed differences in HIV replication capacity between RO and RA cell subsets were not due to inherent differences in cell susceptibility to infection. Our results indicate that HIV replication is enhanced selectively in CD45RO memory phenotype cells through the probable contribution of specialized cellular factors which are produced during CD3-initiated signal transduction. (J. Clin. Invest. 1997. 99:1774-1785.) Key words: T cell immunity • activation $\bullet$ differentiation $\bullet$ viral growth $\bullet$ pathogenesis
\end{abstract}

\footnotetext{
Address correspondence to Dr. C.A. Spina, Department of Pathology (0679), University of California San Diego, 9500 Gilman Drive, La Jolla, CA 92093-0679. Phone: 619-552-7439; FAX: 619-552-7445; E-mail: cspina@ucsd.edu Harry E. Prince's present address is Microbiology Reference Laboratory, Cypress, CA 90630.

Received for publication 19 August 1996 and accepted in revised form 29 January 1997.
}

The Journal of Clinical Investigation

Volume 99, Number 7, April 1997, 1774-1785

\section{Introduction}

Symptomatic HIV infection exhibits many hallmarks of systemic immune activation, including cytokine dysregulation and T cell stimulation (1-4). The life cycle of HIV-1 is particularly well-adapted to a host environment of chronic, active $\mathrm{T}$ cell stimulation. The ability of HIV to establish an infection and replicate to high copy number in CD4 lymphocytes is dependent on both the activation state of the cell and virus-encoded regulatory proteins that modulate viral gene expression. The presence or absence of cellular factors produced during $\mathrm{T}$ cell activation determines whether newly reverse-transcribed, HIV proviral DNA is maintained in an unintegrated or integrated form within the cell (5-8), and whether viral gene transcription progresses from early phase, regulatory products to late phase, structural products (9-11). Of the encoded regulatory proteins essential for high level HIV replication, Rev, Tat, and Nef are known to interact, directly or indirectly, with induced cellular factors $(12,13)$. In addition to regulatory protein-protein interactions, the long terminal repeat (LTR) $)^{1}$ transcriptional promoter region of HIV contains sequence homology to several DNA-binding sites for cellular proteins that are involved in regulation of $\mathrm{T}$ cell gene transcription. LTR homologous binding sites exist for Sp-1, Oct-1, AP-1, NF-AT, $\mathrm{NF}_{\mathrm{k}} \mathrm{B}$, and NRE (12), all of which are induced during the process of $T$ cell activation. It is known that LTR-driven transcription is responsive to cell activation (14-16) and that HIV replication in CD4 lymphocytes is linked stringently to $\mathrm{T}$ cell activation events and cell proliferation (17-19).

Upon $\mathrm{T}$ cell stimulation in vivo, CD4 cells switch expression of membrane CD45 isoforms after induction by specific antigen $(20,21)$. Based on this differential isoform expression, mature CD4 cells in the peripheral circulation have been divided into two reciprocal subsets associated with distinct phenotypes and functions. The high molecular weight isoform, CD45RA, is expressed by immunologically naive CD4 cells and the low molecular weight isoform, CD45RO, is expressed preferentially on the CD4 cell subset containing immunological memory function $(22,23)$. Cells bearing RA and RO phenotypes have been found to differ in activation requirements, lymphokine secretion patterns, and adhesion molecule expression (23-25). Until recently, the maturational switch from RA to RO expression has been believed to be fixed and irreversible; however, new data indicate that some RO cells can convert back to RA expression upon entering a quiescent state in vivo $(26,27)$. With HIV disease, both subset phenotypes appear to be lost in equal proportions from the total CD4 lymphocyte population (28-31), but the functional capacity of the RO cell subset is affected more severely $(28,32-35)$. Addition-

1. Abbreviations used in this paper: LTR, long terminal repeat; TCR, $\mathrm{T}$ cell receptor. 
ally, it has been reported that samples of RO phenotype cells from HIV-infected patients contain 4-10-fold more viral DNA than do cells of the RA phenotype (36). The biologic mechanism by which HIV may interfere selectively with RO cell memory function has remained elusive.

We have been interested in understanding how specific components of $\mathrm{T}$ cell activation pathways can interact to regulate HIV replication. Because the maturational phenotype of CD4 cells impacts its activation response to different stimuli, we have investigated the extent to which RA and RO phenotypic subsets can support HIV infection and replication under different conditions of cell stimulation in vitro. The results from this study demonstrate that HIV replicates preferentially in CD4 lymphocytes expressing the RO memory phenotype when cell activation is induced through the CD3 signal transduction pathway, and that the level of induced HIV replication is not linked directly to the level of induced cell proliferation.

\section{Methods}

Isolation of primary CD4 lymphocytes. Highly enriched preparations of CD4 lymphocytes were isolated from the peripheral blood of healthy, HIV-seronegative donors as described previously (37). Briefly, a lymphocyte fraction was obtained by Ficoll-Hypaque density gradient and monocytes were removed. CD4 lymphocytes were purified by negative selection with the panning method using a mixture of murine monoclonal antibodies specific for CD8, CD16, and CD22 (OKT8, Leu-11b, and Leu-14, respectively). The resulting cell preparations were at least $95 \%$ viable by trypan blue dye exclusion, and contained $94-98 \%$ CD4-positive lymphocytes as monitored by automated flow cytometry using FITC-conjugated monoclonal antibody to CD4 (Leu 3a+b). The isolated CD4 cells were cultured overnight at $37^{\circ} \mathrm{C}$ in RPMI 1640 medium supplemented with L-glutamine $(1 \mathrm{mM})$, penicillin $(50 \mathrm{U} / \mathrm{ml})$, streptomycin $(50 \mu \mathrm{g} / \mathrm{ml})$, and $5 \%$ human AB serum (vol/vol), negative for HIV and HBV antibodies.

Purification of CD $45 R O$ and CD 45RA cell subsets. After physical isolation of $\mathrm{CD} 4$ lymphocytes by negative selection, the population was fractionated further by fluorescence-activated cell sorting $\left(\mathrm{FACS}^{\circledR}\right)$ into reciprocal subsets of positive and negative expressing cells for either the RO or RA isoform of the CD45 membrane receptor. Aliquots of $9-14 \times 10^{7} \mathrm{CD} 4$ cells were stained with either PEconjugated anti-CD45RO or FITC-conjugated anti-CD45RA (clones UCHL-1 and L48, respectively), and separated into positive and negative subsets using a FACStar Plus ${ }^{\circledR}$ flow cytometer (Becton Dickinson Immunocytometry Systems, Mountain View, CA). Nonoverlapping cursor settings were used to limit inclusion of dimly staining cells in the recovered positive subset. After sorting, the isolated negativestaining subsets were purified to $\geq 92 \%$ and the positive-staining subsets, to $\geq 90 \%$.

Virus infection. Infectious virus stocks of the NL4-3 clone of HIV-1 (38) and its isogenic nef deletion mutant $\Delta n e f(37)$ were prepared by transfecting plasmid DNA into the CEM T lymphoblastoid cell line (39) with Lipofectin (40). Working preparations of virus were derived from a single passage of the stock through the CEM line. Infectivity titers based on the $50 \%$ tissue culture infectious dose $\left(\mathrm{TCID}_{50}\right)$ were assessed by terminal dilution microassay with the MT-2 cell line (41). End point titers were determined by p24 antigen assay (Abbott Laboratories, North Chicago, IL). Copies of virion RNA per milliliter in each virus preparation were measured by a bDNA assay (Roche Molecular Systems, Somerville, NJ); and the number of RNA copies per picogram of p24 was calculated. All working preparations of virus used in this study contained $2.5-3$ copies of virion RNA per picogram of $\mathrm{p} 24$.

For infection, virus stocks were diluted in RPMI 1640 medium without serum and without polybrene to achieve equal inoculum doses of $0.5-0.7 \mathrm{pg}$ of p24 per cell (equal to $0.1 \mathrm{TCID}_{50} /$ cell for wild- type NL4-3). Immediately after cell sorting and isolation of the phenotypic subsets, aliquots of $4-6 \times 10^{6}$ quiescent lymphocytes in $1.0 \mathrm{ml}$ were incubated with virus for $16-18 \mathrm{~h}$ at $37^{\circ} \mathrm{C}$. After infection, excess virus was removed by extensive washing with phosphate-buffered saline (PBS, Dulbecco A). Cell recovery was monitored by viable cell count with trypan blue dye exclusion. In experiments using PCR amplification to detect HIV DNA formation, virus preparations were filtered through a $0.45-\mu \mathrm{m}$ membrane before the determination of infectivity titers and quantitation of virion RNA. Our previous studies (42) determined that this procedure minimized potential inoculum contamination from viral DNA associated with cell membrane fragments.

Cell culture and induction of virus replication. After infection, the CD4 lymphocyte fraction and the isolated RO and RA cell subsets were resuspended in RPMI medium with 5\% human AB serum and distributed into 96-well microtiter plates at $10^{5}$ cells/200 $\mu \mathrm{l}$ medium per well in triplicate. Cell stimulation with phytohemagglutinin (PHA-P) and recombinant interleukin-2 (rIL-2) was performed in round-bottom wells (Nunc). Stimulation of cells with immobilized anti-CD3 (Leu-4) and anti-CD28 (clone 9.3) was performed using flat-bottom ELISA plates (Corning) based on a modification of a published method (43). Microtiter wells were coated with $1 \mu \mathrm{g}$ of goat anti-mouse immunoglobulin diluted in $0.05 \mathrm{M}$ carbonate buffer $(\mathrm{pH}$ 9.8 ) by incubation for $90 \mathrm{~min}$ at room temperature; and then washed and incubated with PBS containing $1 \% \mathrm{HAB}$ serum for an additional $30 \mathrm{~min}$. Appropriate dilutions of anti-CD3 and anti-CD28 antibodies were added to replicate wells. After $30 \mathrm{~min}$ of incubation at room temperature, the wells were washed and the cell suspensions in RPMI culture medium were added.

Unstimulated, infected CD4 cells and uninfected cell controls were included for culture. To minimize experimental variation due to individual cell donor differences, a given experimental design was repeated two to four times using primary cells from different donors.

Quantitation of virus infection and replication. Productive virus replication was assessed by measuring soluble p24 antigen released into culture supernates. Samples of $100 \mu l$ were taken from each microculture well after 4 and $7 \mathrm{~d}$ of cell stimulation, and stored at $-80^{\circ} \mathrm{C}$ until completion of the experiment. Batch assays for p24 antigen quantitation were performed by the ELISA method. Supernates from infected, unstimulated cells and from uninfected cells were included as controls. Each p24 value represented the average of triplicate culture wells; equal volumes from the replicate samples were mixed together and the combined sample was then assayed for average p24 content.

Levels of virus infection, achieved in the CD4 cell subsets, were determined by PCR analysis. Cell samples were taken from quiescent cultures at sequential time points and stored at $-80^{\circ} \mathrm{C}$ until the completion of an experiment. Total nucleic acids were extracted by lysing cells with incubation at $50^{\circ} \mathrm{C}$ for $45 \mathrm{~min}$ in a buffer of SDS-NaClEDTA-Tris containing $200 \mu \mathrm{g} / \mathrm{ml}$ proteinase K (44). Nucleic acids were extracted from lysates with phenol-chloroform, precipitated with ethanol, and resuspended in $5 \mathrm{mM}$ Tris ( $\mathrm{pH}$ 8.3). Total DNA per sample was measured by a modification of ethidium bromide, dot blot quantitation (45) and sample aliquots were normalized to equal amounts of total input DNA. PCR amplification of HIV-1 DNA was performed as described previously (42). Reaction mixtures, containing $50 \mathrm{mM}$ Tris $(\mathrm{pH} 8.5), 15 \mathrm{mM}\left(\mathrm{NH}_{4}\right)_{2} \mathrm{SO}_{4}, 2.5 \mathrm{mM} \mathrm{MgCl}{ }_{2}, 10 \mu \mathrm{g}$ bovine serum albumin, $0.2 \mathrm{mM}$ deoxynucleotide triphosphates, and $0.25 \mu \mathrm{g}$ of each oligonucleotide primer, were boiled for $2 \mathrm{~min}$, cooled, and held at $61^{\circ} \mathrm{C}$, and $2.5 \mathrm{U}$ Taq DNA polymerase was added. Amplification was performed for 30 cycles of $94^{\circ} \mathrm{C}$ for $1 \mathrm{~min}, 61^{\circ} \mathrm{C}$ for $1 \mathrm{~min}$, and $72^{\circ} \mathrm{C}$ for $1 \mathrm{~min}$. Two sets of primer pairs were used to amplify different regions of viral DNA based on sequence homology to NL4-3. The region spanning R to U5 within the 5' LTR, U5/LTR, was detected using primers R11 and AA55 $(42,46)$; and the region spanning $\mathrm{R}$ and gag, LTR/gag, with primers M667 and M661 (46). Intersample variation was monitored by parallel PCR reactions measuring total cellular DNA using primers specific for human $\beta$-actin (47) with 20 cycles of amplification. 
Amplification products (5\% of the reaction) were resolved by electrophoresis on nondenaturing, $6 \%$ polyacrylamide gels and electroblotted onto Zeta-Probe nylon membranes. The transferred products were denatured on the membrane with a 15 -min treatment of $0.4 \mathrm{~N}$ $\mathrm{NaOH}$, followed by a brief neutralization with $1 \mathrm{M}$ Tris buffer $(\mathrm{pH}$ 7.4). Blots were hybridized with $\left[\alpha-{ }^{32} \mathrm{P}\right] \mathrm{ATP}-\mathrm{end}-\mathrm{labeled}$ oligonucleotide probes specific for the DNA regions amplified. To detect cDNA products from amplifications using the R11/AA55 and M667/ M661 primer pairs, probe LTR/520 spanning positions 520-539 was used (42). Probe 88-318 (47) was used with primers 317 and 319 to detect cellular $\beta$-actin sequence. Hybridization with $25 \mathrm{ng}$ of probe was performed for $1 \mathrm{~h}$ at $55^{\circ} \mathrm{C}$ in buffer containing $1 \%$ SDS with SSPE, BSA, and polyvinylpyrrolidone and followed by two washes at $55^{\circ} \mathrm{C}$ with $1 \%$ SDS in SSPE. Autoradiography was done with one intensifying screen at $-80^{\circ} \mathrm{C}$ for $1-6 \mathrm{~h}$.

Quantitation of cell proliferation. To determine the levels of cell proliferation generated by the different $\mathrm{T}$ cell stimuli, microcultures were pulsed with $\left[{ }^{3} \mathrm{H}\right]$ thymidine $(2 \mu \mathrm{Ci} /$ well; DuPont, New England Nuclear Research Products, Boston, MA) for 18-24 h on day 3 after stimulation. Cell cultures were harvested onto glass fiber filters with a multiple automated sample harvester (MASH, PHD Cambridge Technology, Watertown, MA) and the amount of isotope incorporation was determined by liquid scintillation $\beta$-emission.

Reagents. The reagents used in cell preparation and culture, and their respective manufacturers, were as follows: Ficoll-Hypaque (Histopaque-1077) and phytohemagglutinin (Sigma Chemical Co., St. Louis, MO); RPMI 1640, L-glutamine, Dulbecco-A PBS, penicillin, and streptomycin (Gibco Laboratories, Grand Island, NY); human AB serum (Gemini Bio-Products, Calabasas, CA); recombinant interleukin-2 (DuPont, New England Nuclear Research Products); and Nunc microculture plates and Corning ELISA plates (Fisher Scientific Co., Tustin, CA). The antibodies used, and their manufacturers, included: goat anti-mouse immunoglobulin (Biosource, International, Camarillo, CA); murine monoclonal antibodies Leu-4, Leu$3 a+b$, Leu-11b, Leu-14, UCHL-1, and L48 (Becton Dickinson Immunocytometry Systems); murine monoclonal antibodies OKT8 (Johnson \& Johnson/Ortho Diagnostics, Raritan, NJ), and 9.3 (generously provided by Dr. Karl-Erik Hellstrom, Bristol-Myers Squibb, Seattle, WA); and HIV p24 ELISA assays (Abbott Laboratories). The reagents used in biomolecular methods, and their manufacturers were: Taq polymerase (Perkin-Elmer Corp., Norwalk, CT); oligonucleotide primers (Genosys Biotechnologies, Inc., The Woodlands, TX); polyacrylamide gels (Novex, San Diego, CA); Zeta-Probe membranes (Bio-Rad Laboratories, Richmond, CA); and HIV bDNA assays (Roche Molecular Systems).

\section{Results}

Cell model for induction of $T$ lymphocyte proliferation and $H I V$ replication. To evaluate conditions of $\mathrm{T}$ cell activation that induce HIV replication, an in vitro model of acute virus infection in primary CD4 cells was used (37). Preparations of negatively selected CD4 lymphocytes, purified from the peripheral blood of healthy, HIV-seronegative donors, were infected in a quiescent state by a 3-h incubation with the NL4-3 clone (38) of HIV-1. 1-4 d after infection, mitogenic stimuli were added to CD4 cell microcultures, and levels of induced cell proliferation and productive virus replication were determined. In our prior studies (37), a high concentration of PHA mitogen $(3 \mu \mathrm{g} / \mathrm{ml})$ in combination with exogenous rIL-2 was used to ensure optimal stimulation of purified CD4 cell cultures in the absence of accessory cells. It is known that PHA provides a potent stimulus to $\mathrm{T}$ cells by engaging both CD3 and CD2 surface membrane receptors (48). In the natural, in vivo setting of antigen stimulation of $T$ cells, a positive response is dependent on simultaneous engagement of the T cell receptor (TCR)/CD3 complex and the CD28 receptor on the $\mathrm{T}$ cell membrane $(49,50)$ by the antigen-presenting cell. This dual-signal induction response for $\mathrm{T}$ cell activation can be mimicked in vitro by physically cross-linking the CD3 and CD28 receptors with immobilized monoclonal antibodies (43). In our present study, we compared the effectiveness of a range of PHA concentrations, in the presence or absence of exogenous rIL-2, with the two-signal induction response using immobilized antibodies to CD3 and CD28. Costimulation of infected CD4 lymphocytes through their CD3 and CD28 membrane receptors resulted in significantly greater, and earlier, HIV production compared with stimulation achieved with an optimal concentration of PHA in the presence of rIL-2 (Table I). A high dose of immobilized anti-CD3 (12.5 ng/well) was capable of inducing substantial cell proliferation and virus replication without a requirement for anti-CD28 costimulus. However, when the amount of anti-CD3 was decreased by fourfold dilutions, both cellular and viral responses became dependent on addition of the anti-CD28 second signal (Table I). Based on these results, concentrations of PHA mitogen and immobilized anti-CD3 antibody were chosen to test the responsiveness of separated, phenotypic subsets of CD4 lymphocytes.

We proposed to use $\mathrm{FACS}^{\circledR}$ to purify CD45RA (RA) and CD45RO (RO) phenotypic cell subsets (20-22) from the preparations of isolated CD4 lymphocytes. Before proceeding, experiments were performed to determine the effects of antibody binding on the ability of CD4 cells to respond to proliferative stimulus. Aliquots of CD4 cells were stained with

Table I. Stimulation Conditions for Induction of CD4 Cell Proliferation and HIV Replication

\begin{tabular}{|c|c|c|c|c|c|}
\hline \multirow[b]{2}{*}{ Stimulus $^{\S}$} & \multirow[b]{2}{*}{$n$} & \multicolumn{2}{|c|}{ Proliferation* } & \multicolumn{2}{|c|}{ HIV Replication ${ }^{\ddagger}$} \\
\hline & & Day 2 & Day 4 & Day 4 & Day 7 \\
\hline & & \multicolumn{2}{|c|}{$c p m \times 10^{3}$} & \multicolumn{2}{|c|}{$p 24(n g / m l)$} \\
\hline 0 & (2) & 4 & 4 & 1 & 1 \\
\hline Anti-CD28 & & 4 & 4 & 1 & 1 \\
\hline Anti-CD3, $12.5 \mathrm{ng}$ & (2) & 185 & 213 & 21 & 192 \\
\hline+ anti-CD28 & & 242 & 432 & 39 & 384 \\
\hline Anti-CD3, 3 ng & (2) & 20 & 9 & 2 & 7 \\
\hline+ anti-CD28 & & 218 & 306 & 140 & 553 \\
\hline Anti-CD3, $0.8 \mathrm{ng}$ & (2) & 1 & 1 & 1 & 2 \\
\hline+ anti-CD28 & & 154 & 168 & 70 & 406 \\
\hline PHA, $0.3 \mu \mathrm{g} / \mathrm{ml}$ & (4) & 10 & 3 & 10 & 34 \\
\hline$+\mathrm{IL}-2$ & & 58 & 31 & 73 & 122 \\
\hline PHA, $0.6 \mu \mathrm{g} / \mathrm{ml}$ & (4) & 48 & 8 & 24 & 84 \\
\hline$+\mathrm{IL}-2$ & & 92 & 38 & 77 & 183 \\
\hline PHA, $3 \mu \mathrm{g} / \mathrm{ml}$ & (4) & 152 & 123 & 30 & 306 \\
\hline$+\mathrm{IL}-2$ & & 154 & 144 & 45 & 293 \\
\hline
\end{tabular}

* Proliferation measured by $18-20$-h pulse with $\left[{ }^{3} \mathrm{H}\right]$ thymidine on days 2 and 4 after stimulation. Resting CD4 cells infected with NL4-3 (MOI = $0.1), 4 \mathrm{~d}$ before addition of stimuli. Average of $n$ experiments. ${ }^{\ddagger} \mathrm{HIV}$ replication measured by soluble p 24 production on days 4 and 7 after stimulation. ${ }^{\S}$ Anti-CD28 antibody (9.3), 1/10,000 final dilution. Anti-CD3 antibody (Leu-4), concentration in ng/well. PHA concentration in $\mu \mathrm{g} /$ ml. rIL-2, $5 \mathrm{U} / \mathrm{ml}$. 
Table II. Retention of Anti-CD45 Antibodies on Stained CD4 Lymphocytes

\begin{tabular}{|c|c|c|c|c|}
\hline \multicolumn{2}{|c|}{ Antibody staining* } & \multicolumn{2}{|c|}{$\begin{array}{l}\text { \% Positive CD4 cells }{ }^{\ddagger} \\
\text { after culture in }\end{array}$} & \multirow[b]{2}{*}{ Proliferation $^{\S}$} \\
\hline Day 0 & Day 3 & Medium & Anti-CD3 & \\
\hline & & & & $c p m \times 10^{3}$ \\
\hline None & None & - & - & 43 \\
\hline None & Anti-RA & 76 & 72 & - \\
\hline Anti-RA & None & 1 & 1 & 48 \\
\hline Anti-RA & Anti-RA & 75 & 69 & - \\
\hline None & Anti-RO & 79 & 81 & - \\
\hline Anti-RO & None & 53 & 44 & 46 \\
\hline Anti-RO & Anti-RO & 80 & 75 & - \\
\hline
\end{tabular}

* On days 0 and 3, isolated CD4 lymphocytes were treated with either medium alone, or monoclonal antibody to CD45RA (FITC) or CD45RO (PE). ${ }^{*}$ Cells were cultured with medium alone or with the addition of immobilized anti-CD3 (3 ng/well). After $3 \mathrm{~d}$, the percentage of total CD4 cells expressing CD45RA (FITC) or CD45RO (PE) was determined. Percentages include the double-positive subset of $\mathrm{RA}^{\mathrm{dim} /}$ $\mathrm{RO}^{\mathrm{dim}}$. ${ }^{\S}$ Proliferation was measured by a 6 -h pulse with $\left[{ }^{3} \mathrm{H}\right]$ thymidine on day 3 after stimulation.

anti-RA-FITC or anti-RO-PE monoclonal antibodies and then cultured for $3 \mathrm{~d}$ in medium alone or in the presence of immobilized anti-CD3. After culture, the percentage of cells retaining the original conjugated antibody on their surface and their proliferative responses were measured (Table II). Anti-RA antibody was shed from the cultured cells whether they were unstimulated or stimulated, but anti-RO antibody was retained on a majority of the cells, even after activation. In both cases, however, the proliferative responses were the same as that of the unstained cell aliquot (Table II). These preliminary experiments reassured us that isolation of the RA and RO subsets by FACS ${ }^{\circledR}$ would not alter their capacity to respond to T cell stimuli.

Purification of RO and RA phenotypic subsets. Before infection and culture, a portion of the CD4 lymphocyte preparation was fractionated by FACS ${ }^{\circledR}$ into reciprocal subsets of positive and negative expressing cells for either the RO or RA isoform of the CD45 membrane antigen. In the first set of experiments, cells were sorted based on staining with PE-conjugated, anti-RO antibody. With a group of four healthy donors, the starting percentages of the stained subsets were $50 \pm 6 \%$ (mean $\pm 1 \mathrm{SD}$ ) for the RO-positive fraction, and $42 \pm 6 \%$ for the RO-negative fraction. After sorting by FACS ${ }^{\circledR}$, the ROpositive (memory) subset was purified to $92 \pm 1 \%$ and the ROnegative (naive) subset was purified to $96 \pm 3 \%$. Single antigen selection of these subsets does not result consistently in the recovery of true reciprocal memory and naive phenotype populations, because the RO-negative subset is not always equivalent to a $\mathrm{RA}^{\text {bri }}$-positive subset $(26,27)$. To ensure that CD4 cell fractionation based on RO staining would not inadvertently skew results obtained with subsequent cell-induction experiments, three of the cell donors were retested using subsets isolated with FITC-conjugated, anti-RA antibody staining. In this format, the starting subset percentages were $44 \pm 2 \%$ for the RA-positive fraction, and $48 \pm 2 \%$ for the RA-negative fraction. After sorting, the RA-positive (naive) subset was purified to $91 \pm 3 \%$ and the RA-negative (memory) subset was purified to $95 \pm 3 \%$. Fig. 1 shows the results from representative sorting procedures. Although cursors were set to exclude the dimly stained fraction of either RO or RA positive cells, the inherent staining pattern of CD45RA expression made it more difficult to separate $\mathrm{RA}^{\text {bri }}$ cells from RA ${ }^{\text {dim }}$ cells.

$H I V$ replication in the $R O$ and $R A$ subsets of $C D 4$ cells. Levels of HIV replication induced by PHA mitogen stimulation were compared with levels of virus replication achieved by
PRE-SORT
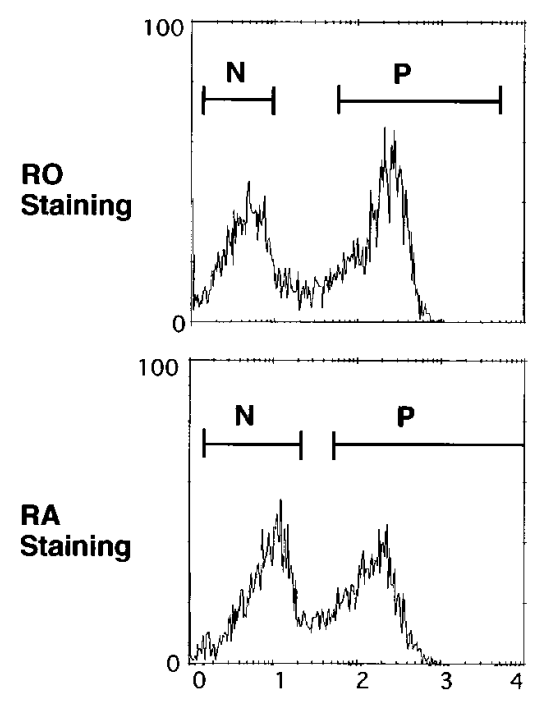

Negative Subset
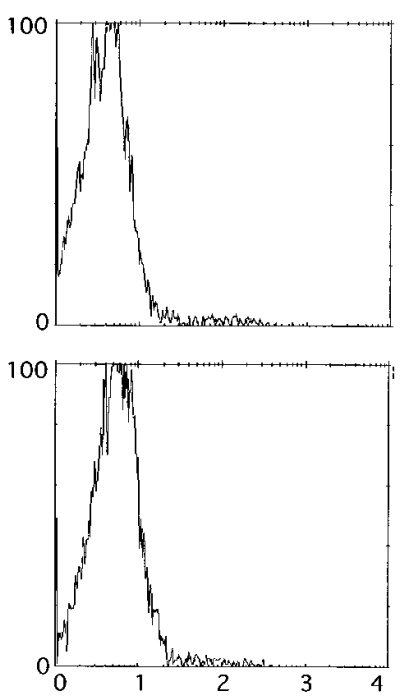

Intensity of Fluorescence
Figure 1. Purification of negative and positive cell subsets using CD45RO and CD45RA staining. CD4 lymphocytes, isolated by negative selection, were stained with either PE-conjugated anti-RO or FITC-conjugated anti-RA antibody and sorted into negative and positive subsets by FACS $^{\circledR}$. Cursors were set to minimize the inclusion of dimly stained cells in the recovered positive subset. Histograms are shown for the stained, unsorted cells (PRE$S O R T$ ) and for the recovered negative- and positive-staining subsets (POST-SORT) using a 4-log scale of fluorescent intensity. Figure depicts results from two representative cell sorts. 
A

PHA \pm IL-2

CD4
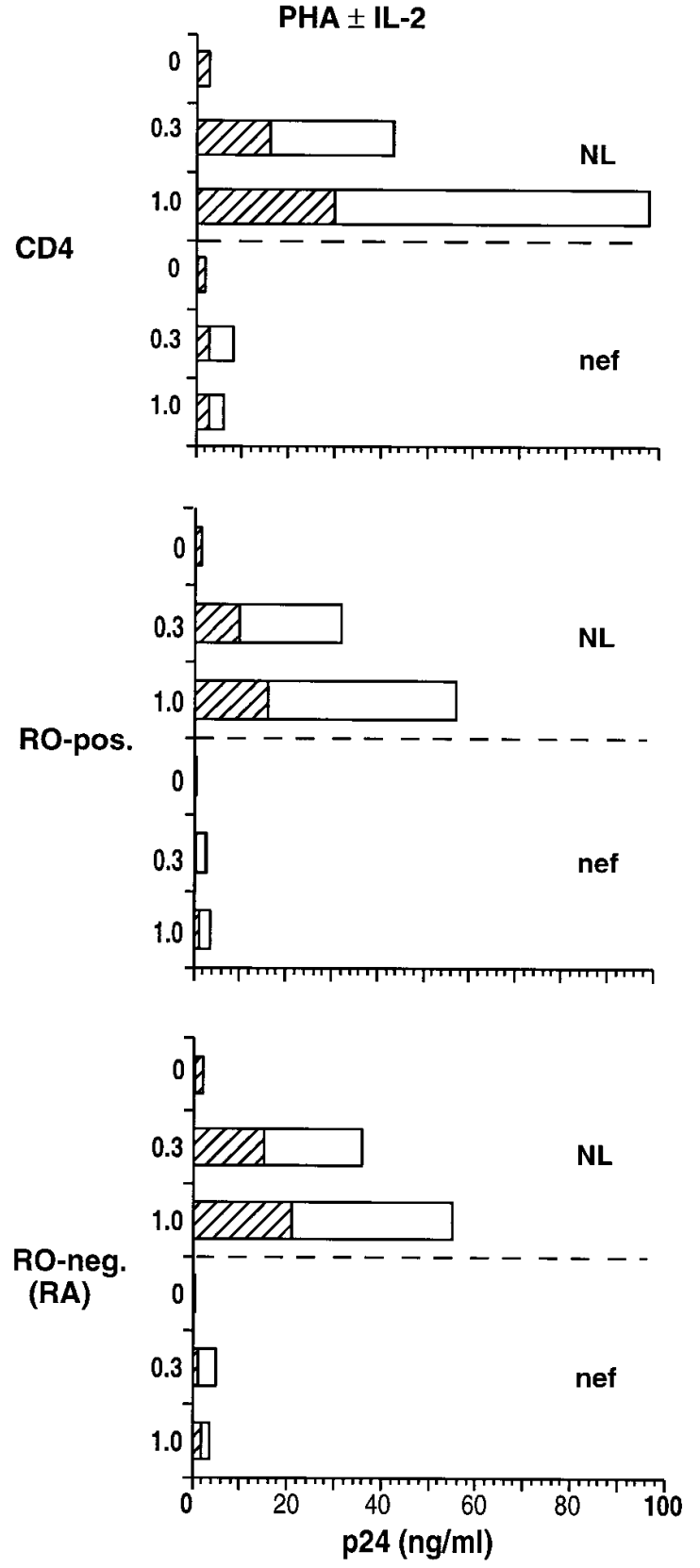

B
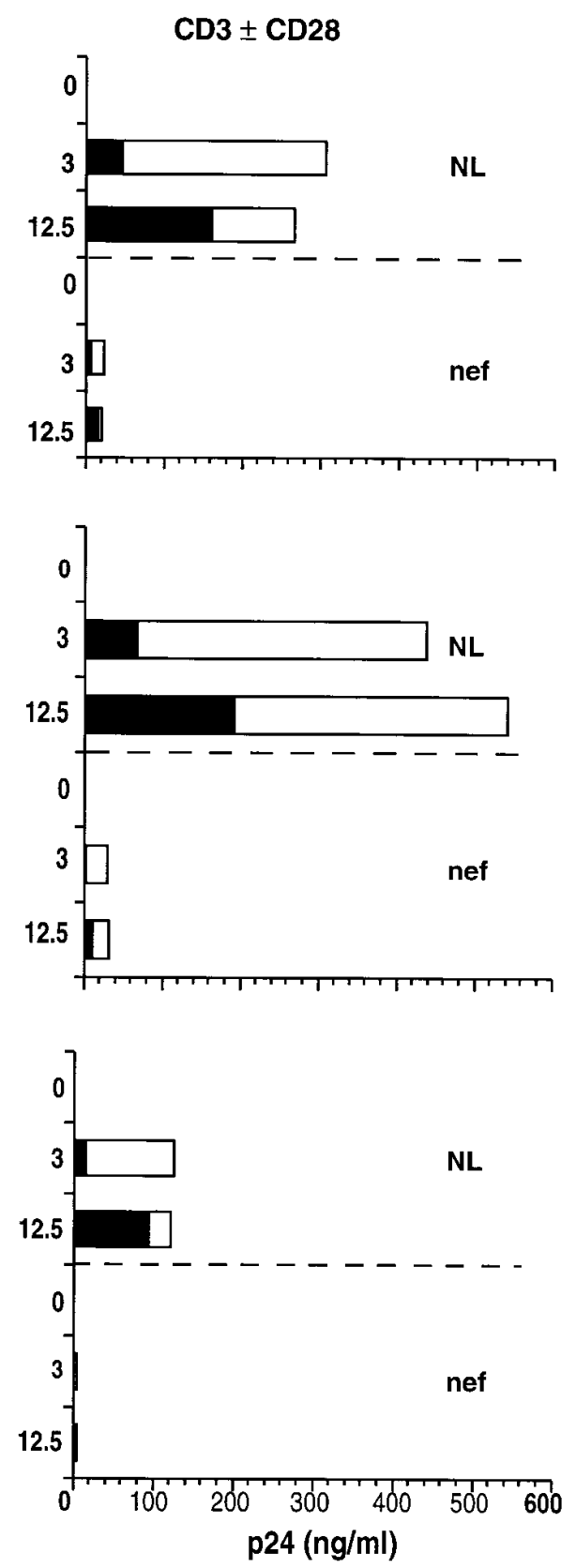

Figure 2. Induction of HIV replication in RO and RA subsets of CD4 cells. Primary CD4 lymphocytes were FACS ${ }^{\circledR}$-sorted into RO-positive and RO-negative subsets, based on positive selection using anti-RO monoclonal antibody. Total CD4 cells and the isolated cell subsets were infected with the NL4-3 and $\Delta n e f$ clones of HIV-1 for $18 \mathrm{~h}$ before the addition of cell stimuli. T cell activation was induced by the addition of: $(A)$ PHA mitogen at 0.3 and $1 \mu \mathrm{g} / \mathrm{ml}$, alone (striped bars) or in the presence of $5 \mathrm{U} / \mathrm{ml}$ exogenous rIL-2 (white bars); or $(B)$ immobilized anti-CD3 antibody at 3 and $12.5 \mathrm{ng} /$ well, alone (black bars) or in the presence of costimulatory anti-CD28 antibody (white bars). Soluble p24 antigen production was measured on day 7 after cell stimulation in microcultures infected with NL4-3 $(N L)$ or $\Delta n e f$. Data represent the mean values of four experi-

ments, using cell preparations from different donors.

anti-CD3 cross-linking in subsets of infected, memory and naive phenotype cells. Primary CD4 cells were sorted into ROpositive and RO-negative (RA) subpopulations by FACS ${ }^{\circledR}$. Total CD4 cells and the sorted subsets were infected with wildtype NL4-3 virus $18 \mathrm{~h}$ before the addition of stimuli. 4 and $7 \mathrm{~d}$ after cell activation, replicate microcultures were sampled for production of soluble p24, HIV antigen. In unfractionated CD4 cells, $7 \mathrm{~d}$ of costimulation with immobilized anti-CD3 plus anti-CD28 (Fig. 2 B) produced approximately threefold greater HIV replication than did stimulation with an optimal concentration of PHA in the presence of rIL-2 (Fig. $2 \mathrm{~A}$ ). Levels of virus replication in the $\mathrm{RO}$ and $\mathrm{RA}$ subsets were similar after PHA induction; however with anti-CD3/anti-CD28 stimulation, the RO subset produced four- to sixfold more HIV than did the RA subset (Fig. 2, $A$ and $B$ ). Less virus was induced from infected RA cells in response to anti-CD3 stimu- 
lus, alone or in combination with anti-CD28. In contrast to the significant additive effect of CD28 costimulation on HIV induction from the RO subset, only minor increments in virus replication were produced in the RA subset by addition of anti-CD28 to anti-CD3 stimulus (Fig. $2 \mathrm{~B}$ ). The relative difference in the capacity of RO and RA cell subsets to support HIV replication was even more apparent when cultures were sampled early after CD3 induction. Although the levels of measured p24 were lower overall after $4 \mathrm{~d}$ of cell stimulation, the difference in relative levels of virus replication between RO and RA cells was greater: 20-35-fold at day 4 compared with 4-6-fold at day 7 (data not shown). HIV replication was high initially in the RO cell subset and approached a plateau level by day 7; however in the RA subset, viral replication began at a low level and continued to increase exponentially between 4 and $7 \mathrm{~d}$ of culture. These results indicated that stimulation of HIV-infected, CD4 cells through CD3/CD28 signal induction provides an enhanced cellular environment for virus replication preferentially in the RO phenotype subset associated with $\mathrm{T}_{\mathrm{H}}$ memory function.
A
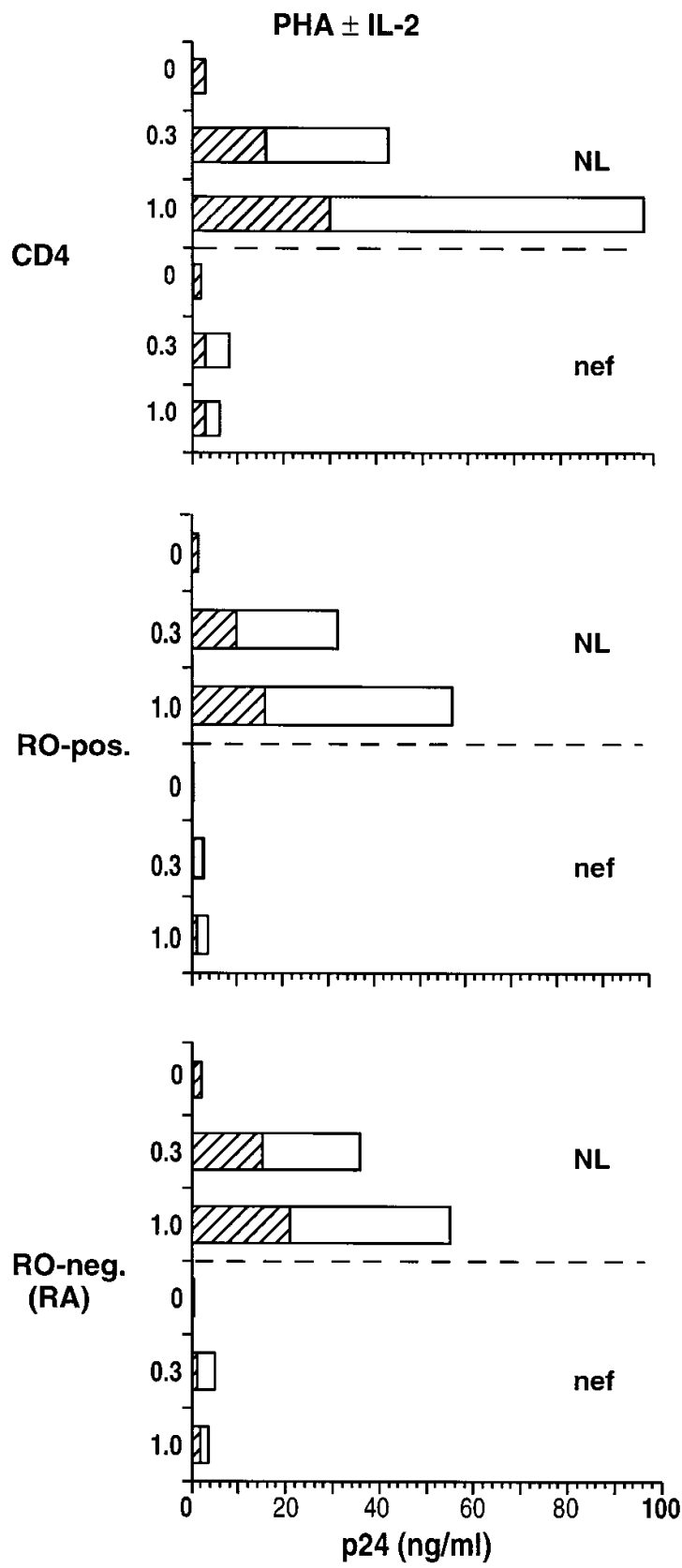

B
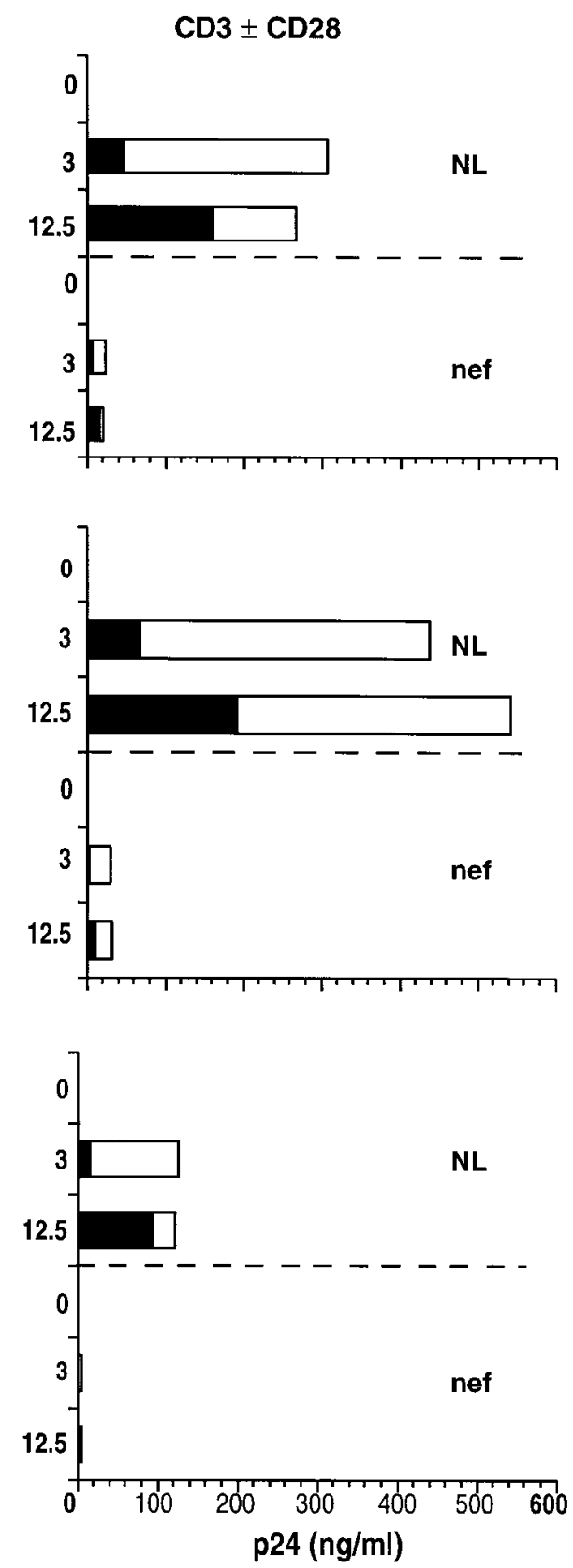

Figure 3. Induction of cell proliferation in RO and RA subsets of CD4 cells. Separate cell aliquots were taken from the experiments described in Fig. 1; and cell proliferation was measured on day 4 after stimulation with $(A)$ PHA with (white bars) or without (striped bars) rIL-2 or (B) antiCD3 with (white bars) or without (black bars) anti-CD28, in HIV-infected cells ( $N L$ or nef) compared with uninfected cell controls (CC). Data represent the mean values of three experiments. 
In addition to the requirement for cellular factors provided through activation, HIV replication is also influenced significantly by viral regulatory gene products (12). A prior report from our laboratory demonstrated that the nef gene of HIV-1 is critical to virus replication in primary CD4 cells (37). To examine the contribution of nef function to HIV replication in the major, maturational subsets of CD4 lymphocytes, infection of RO and RA cells with the $\Delta n e f$ isogenic mutant of NL4-3 (37) was performed in parallel. As expected, the $\Delta$ nef virus had a significantly reduced capacity $(\sim 1 \log )$ to replicate in CD4 cells, after induction with PHA (Fig. $2 A$ ). No difference was seen in the ability of PHA-induced, RO and RA cell subsets to support replication of the nef mutant. Induction of infected CD4 cells with anti-CD3 with or without anti-CD28 stimulation resulted in a similar $1 \log$ difference in viral replication levels between $\Delta n e f$ and parental NL4-3 clones (Fig. $2 B$ ). However, in this case most of the detected $\Delta$ nef replication occurred in the RO cell subset. $7 \mathrm{~d}$ after cell stimulation, the level of $\Delta n e f$ replication in RO cells was ninefold greater than it was in RA cells. In comparison, the relative difference in wild-type NL4-3 replication between the two cell subsets was fivefold. It appeared that a lack of nef function affected HIV replication capacity more severely in an RA, naive cell environment responding to anti-CD3 induction.

Levels of cell proliferation induced in $R O$ and $R A$ phenotypic subsets. To determine any relationship between the levels of HIV replication obtained in RO and RA cell subsets and the levels of cell proliferation induced, separate microcultures of infected and uninfected cell samples were assessed for $\left[{ }^{3} \mathrm{H}\right]$ thymidine uptake in parallel with the viral replication assays described above (three of four donors). Replicate cultures were harvested for analysis after $4 \mathrm{~d}$ of stimulation. Overall, induction with anti-CD3 in combination with anti-CD28 produced levels of cell proliferation that were at least fivefold greater than those induced with PHA plus rIL-2 (Fig. 3). In uninfected cell cultures, the RA subset proliferated to approximately twice the level of the RO subset, using both types of induction stimuli (Fig. 3). Cultures infected with NL4-3 or $\Delta n e f$ virus did not exhibit proliferation patterns different from that of the corresponding uninfected cell control, except for NL4-3

A
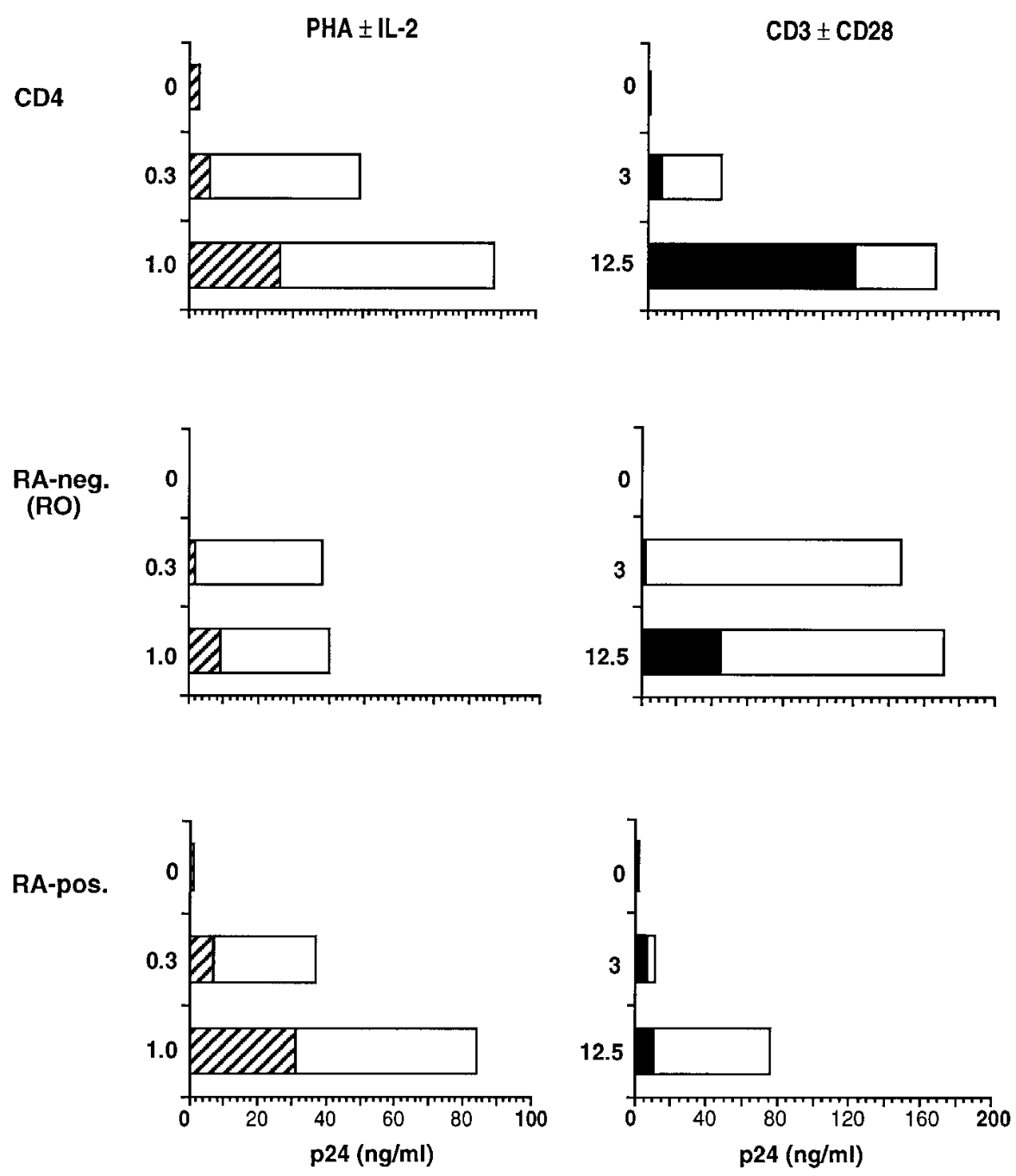

Figure 4. Comparison of induced cell proliferation and HIV replication in CD4 cells sorted by CD45RA selection. CD4 cells were FACS ${ }^{\circledR}$-sorted into RA-positive and RA-negative subsets based on positive selection using anti-RA monoclonal antibody. The unseparated and sorted cell populations were infected with NL4-3 $(\mathrm{MOI}=0.1)$ for $18 \mathrm{~h}$ before the addition of stimuli. HIV production $(A)$ and cell proliferation $(B)$ were measured after stimulation on days 4 and 7, respectively. Data represent the average of three experiments with different cell donors. Left columns: striped bars, PHA; white bars, PHA plus IL-2. Right columns: black bars, anti-CD3; white bars, anti-CD3 with anti-CD28. 
infection of RO cells. Under conditions of CD3 plus CD28 costimulation, RO cells infected with wild-type NL4-3 proliferated to $55 \%$ of the uninfected, cell control level (Fig. $3 B$ ). The majority of this reduction was confined to that portion of the response elicited through $\mathrm{CD} 28$ costimulation. In comparison, RO cells infected with the $\Delta$ nef mutant did not exhibit any significant reduction in proliferative response. Reduction of RO cell proliferative response during wild-type infection was not attributable to overt viral cytopathic effects, because no appreciable cell death occurred at this early time point. The pattern of proliferation, induced in the CD4 cell subsets by CD3/CD28 costimulation, was in direct contrast to the pattern of induced HIV replication. Although the RA subset proliferated to twice the level of the RO subset, HIV replication occurred preferentially in the stimulated RO cell subset (Figs. $2 \mathrm{~B}$ and $3 \mathrm{~B}$ ). These results demonstrated that the capacity of primary CD4 cells to support HIV replication is not linked solely to the capacity of cells to proliferate. Both the maturational stage of the cell and the engagement of specific signaling pathways contributed to the resulting level of virus production in memory and naive phenotypic subsets.

Comparison of results using cell subsets selected with CD45RA staining To ensure that the initial method used to isolate reciprocal cell populations of memory and naive phenotypic subsets did not influence the outcome of functional assays, additional experiments were performed using anti-RA antibody selection. CD4 lymphocytes were separated into RApositive and RA-negative (RO) subsets by FACS ${ }^{\circledR}$. Assays of viral replication and cell proliferation were repeated using cell preparations from three of the original donors. The relative patterns of HIV replication (Fig. $4 A$ ) and T cell proliferation (Fig. $4 B$ ), seen in the reciprocal cell subsets, were not significantly different from those obtained with cells fractionated by anti-RO antibody selection. Some alterations in the magnitude of proliferation were noted in response to the additive effect of anti-CD28 costimulation (Fig. $4 \mathrm{~B}$ ). These data confirmed our prior results.

Susceptibility of $R O$ and $R A$ cell subsets to viral infection. It was possible that the difference in HIV replication observed between RO and RA cell subsets was due to a relative difference in cell susceptibility to infection. Because the differences in viral replication were selective for anti-CD3 induction and were not enhanced by multiple infection cycles, it seemed unlikely that variation in HIV infectivity was the cause for such results. To clarify our interpretation of these data, PCR analysis was performed for HIV DNA formation after viral infec-

B

CD4
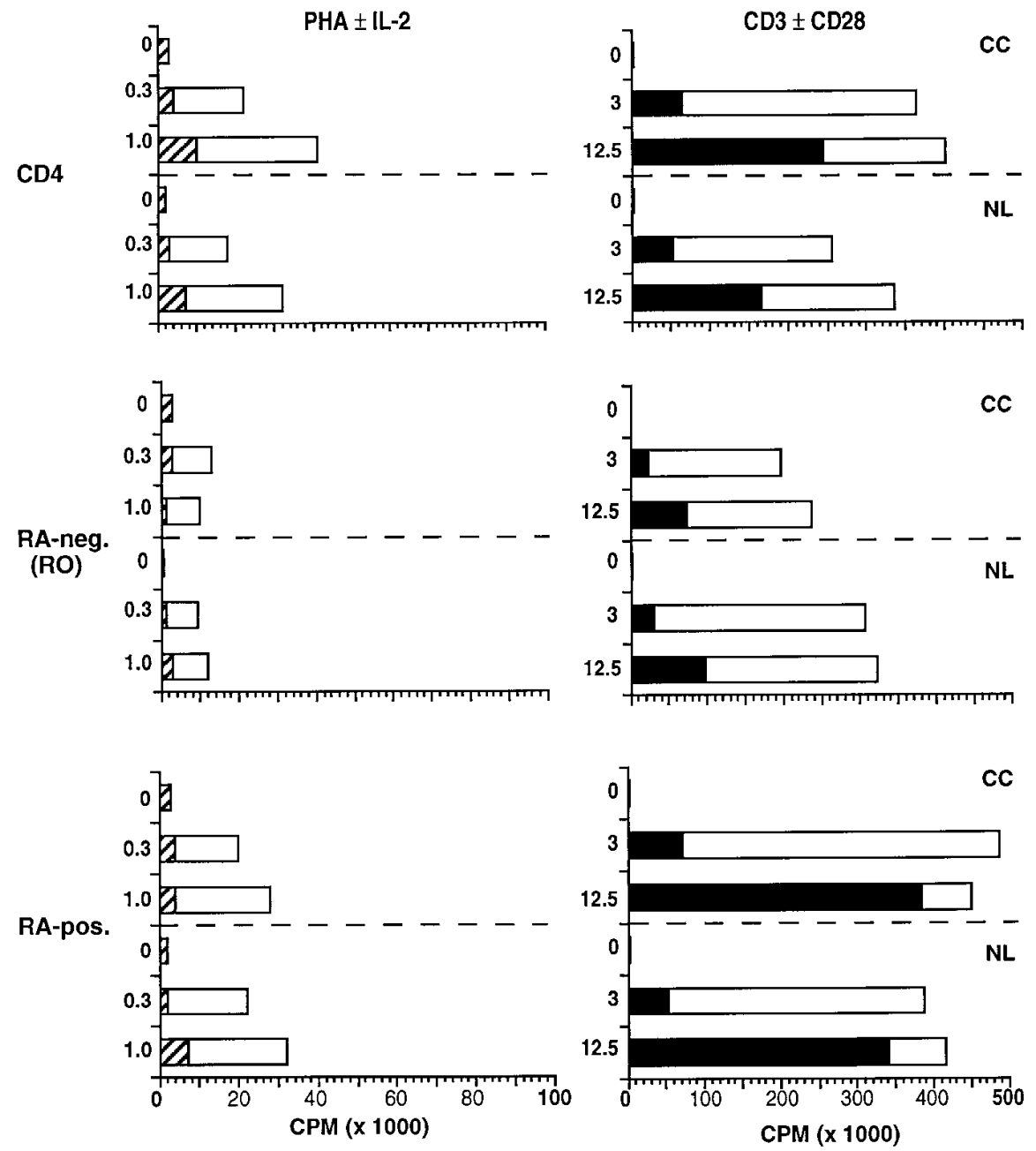

Figure 4 (Continued) 


\section{A}
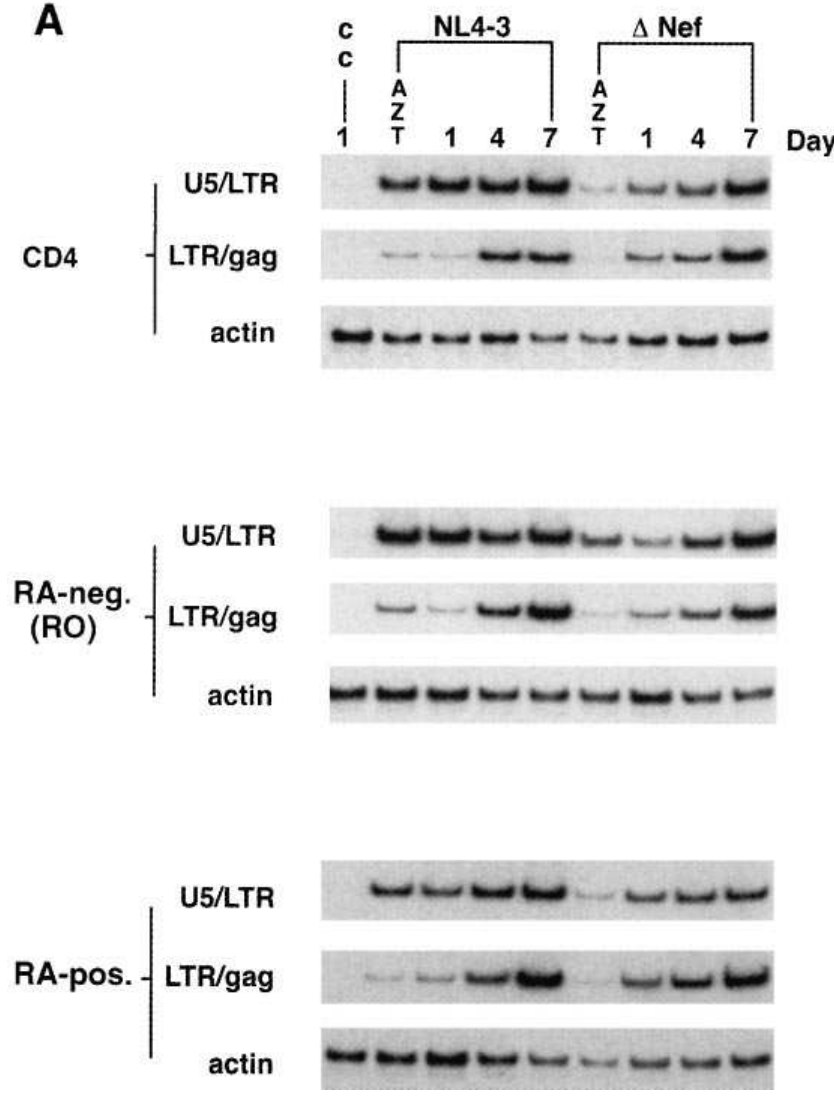

B

\section{HIV DNA STANDARD}

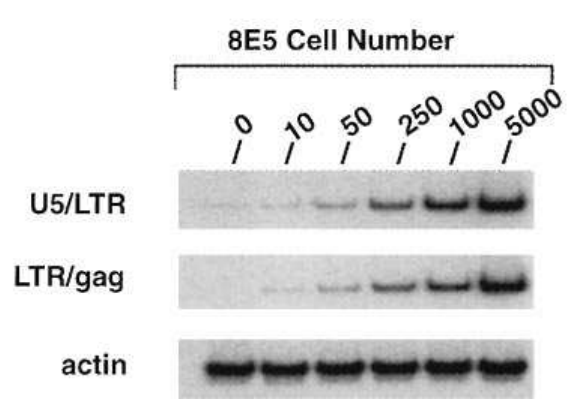

Figure 5. PCR analysis of HIV infectivity in CD45RO and CD45RA cell subsets. CD4 cells were $\mathrm{FACS}^{\circledR}$-sorted into RO and RA subsets using anti-CD45RA antibody selection. Total CD4 cells and the isolated cell subsets were infected with NL4-3 and $\Delta$ nef for $18 \mathrm{~h}$ and washed extensively to remove excess virus. Cells were cultured without stimulation; cell samples were taken immediately after infection (day 1), and at 4 and $7 \mathrm{~d}$ after infection. Nucleic acids were extracted, and total genomic DNA was equalized to $35 \mathrm{ng}$ per sample using a modified ethidium bromide quantitation method. ( $A$ ) PCR amplification was performed using primer pairs detecting initial reverse-transcribed (U5/LTR) and full-length, minus strand (LTR/gag) DNA species of HIV. Day 1 samples of uninfected cell controls $(C C)$ and cells infected in the presence of $3 \mu \mathrm{M}$ AZT were analyzed in parallel. Amplification of cellular $\beta$-actin was included as a control for intersample variation. $(B)$ The HIV-infected cell line 8 E5 was diluted serially into a cell background of primary CD4 cells to derive a HIV DNA standard curve for relative quantitation. Autoradiography was done for $2 \mathrm{~h}$ for HIV DNA and $3 \mathrm{~h}$ for cellular $\beta$-actin. tion. RA-positive and RA-negative cell subsets were obtained by FACS ${ }^{\circledR}$ selection. Total CD4 cells and the separated cell subsets were infected with the NL4-3 and $\Delta$ nef clones for $18 \mathrm{~h}$, washed extensively to remove excess inoculum, and maintained in culture without stimulation. Aliquots of uninfected cells and cells infected in the presence of azidothymidine (AZT) were included as controls. Cell samples were taken immediately after infection (day 1) and on days 4 and 7 after infection. PCR amplifications were done using primer pairs to detect both early (U5/LTR) and late (LTR/gag) species of HIV-1 DNA $(6,42)$. Fig. 5 shows the results from a representative experiment. No difference was detected in the amounts of early viral DNA found in RO and RA subsets after incubation with NL4-3, indicating equal HIV infection of the cell subsets. In addition, the kinetics and quality of RT processing to late, viral DNA species appeared equal in RO and RA cells. Overall, infection with the $\Delta$ nef mutant produced levels of viral DNA formation that were lower than those detected with NL4-3, wild-type infection (Fig. 5). However, there was no difference in the amount or kinetics of $\Delta n e f$ DNA formation seen between infection of the RO and RA cell subsets. The same experimental design was repeated using three different cell donors, and the results were similar in each experiment. These data demonstrated that observed differences between RO and RA subsets to support HIV replication are not due to differences in relative cell susceptibility to infection.

\section{Discussion}

Taken in their entirety, the results from this study demonstrate that memory phenotype, CD4 lymphocytes support high levels of HIV replication selectively through the contribution of specialized cellular factors, generated from engagement of the CD3/TCR transduction pathway. We have used an in vitro model that physically cross-links CD3 and CD28 membrane receptors with immobilized antibodies to mimic the biologically relevant, dual-signal induction response that occurs during antigen presentation for T cell clonal expansion $(49,50)$. In this experimental model, cross-linking of the CD3 receptor in combination with the CD28 coreceptor provided a very potent stimulus for primary CD4 cell proliferation. Use of anti-CD3/ anti-CD28 costimulus generated a proliferative response that was consistently fivefold greater than that of optimal PHA mitogen stimulation in the presence of exogenous IL-2. In concert with enhanced cell proliferation, stimulation by anti-CD3/ anti-CD28 produced approximately threefold higher levels of induced HIV replication than did PHA stimulation in infected CD4 lymphocytes. Our results differ from those of a recent report (51) that showed inhibition of HIV infection by anti-CD3/ anti-CD28 costimulation. In contrast to our experimental design using infection of resting cells followed by induction with T cell stimuli, these investigators prestimulated PBMC or CD4 lymphocyte cultures for $3 \mathrm{~d}$ before infection with a lowgrowth, monocyte-trophic strain of HIV. It is possible that levels of membrane expression for the CD4 receptor and/or the chemokine coreceptors of HIV (52) are modulated in a transient, or sustained, manner after CD28 costimulation, and this could affect cellular capacity for viral binding and entry.

Patterns of differential HIV response to T cell stimuli, similar to those seen with in vitro models, have been reported for peripheral blood lymphocytes taken from HIV-infected subjects $(28,32,33,35)$. Not all $\mathrm{T}$ cell stimuli have been found to 
be equivalent in their capacity to induce productive viral replication from CD4 cells of HIV-infected patients. Although the best inducers of in vitro HIV replication, such as lectins and immobilized antibodies to CD3, share strong mitogenic properties, the ability of a stimulus to produce cell proliferation has not always correlated directly with its capacity to induce virus replication in cells from HIV patients $(28,35,53-55)$. Most recently, data generated from patient samples have demonstrated that in vitro induction with immobilized anti-CD3 plus anti-CD28 results in a loss of HIV-producing cells and a preferential survival of uninfected CD4 cells during long-term culture (51). The authors of this study also arrived at a conclusion similar to ours, that individual routes of $\mathrm{T}$ cell activation result in differential effects on the ability of HIV to replicate.

In addition to the effects ascribed to different $T$ cell stimuli, the maturational state of CD4 lymphocytes also influences both the degree of cell proliferation and the capacity to support productive HIV replication. In agreement with prior studies $(23,33,35,56)$, we have found that cells expressing the naive, CD45RA phenotype proliferate to higher levels (approximately twofold) in response to mitogens than do cells with the memory, CD45RO phenotype. Despite their proliferative advantage, RA cells supported less HIV growth than RO cells, when induction occurred through the CD3 activation pathway. If PHA mitogen was used to stimulate the infected CD4 cell subsets, RA and RO cells produced similar amounts of virus. Studies that have used isolated cell subsets from HIVinfected subjects have reported similar findings (30, 34-36, 57). PHA stimulation has been found consistently to generate HIV replication equally in naive and memory phenotype cells (3436); whereas, stimulation with immobilized anti-CD3 antibodies has induced virus replication preferentially in the memory cell subset from HIV-infected patients $(30,35,57)$. It has been suggested that the RO and RA isoforms of membraneexpressed CD45 may deliver quantitatively different activation signals influencing the CD4 and CD3 receptor pathways (58, 59). It is known that the phosphatase activity of CD45 is essential for activation of CD4-associated p56/lck during triggering of the TCR/CD3 signaling cascade (59). The results from our study, as well as the findings with HIV-infected subjects (35, $53,54,57)$, indicate that cell proliferation per se is less critical for support of HIV growth than is the specific, cell activation pathway engaged. This premise is bolstered by work from another laboratory, demonstrating that RA cells support minimal HIV replication, when induced to proliferate using a cytokine stimulus that maintains their RA phenotype (60).

Along with requirements for cell activation factors, HIV replication is dependent on viral factors that mediate a positive regulatory feedback $(11,12)$. The nef gene of HIV -1 has been identified as a member of the group of essential, viral regulatory genes (13). The mechanism and action of Nef protein product remain unclear; however, accumulating data suggest that Nef positively affects viral replication capacity indirectly through interaction with components of T cell activation pathways $(13,61-64)$. Expression of Nef in vitro has been demonstrated to cause perturbation of normal $\mathrm{T}$ cell functions, including downregulation of CD4 receptor expression $(65,66)$, IL-2 gene transcription (67), and $\mathrm{NF}_{\mathrm{k}} \mathrm{B}$ and $\mathrm{AP}-1$ induction $(68,69)$. In prior studies with our primary CD4 cell model, we have found that nef exerts a significant positive influence on HIV replication during induction from a preexisting latent state in quiescent lymphocytes (37). Using a deletion mutant of nef, we have now examined whether nef function is affected by the maturational state of the infected CD4 target cell. With PHA induction, the nef mutant of HIV was crippled severely in its ability to replicate in both RO and RA cells; but in the setting of CD3 stimulation, the lack of nef resulted in a more selective loss of HIV replication capacity within the RA cell subset. These data suggest that nef gene function may be critical in vivo for HIV infection and replication in naive phenotype cells.

In our in vitro model, enhanced replication of HIV in RO phenotype cells is dependent on the specific use of CD3 stimulation; therefore, we have not interpreted these results to be indicative of preferential HIV infection of the RO subset. However, other investigators have reported finding increased levels of HIV DNA in memory phenotype CD4 cells from $\mathrm{HIV}$-infected patients and after acute infection of control cells in vitro (36). To examine relative levels of HIV infection that were achieved in our experiments, PCR amplifications for viral DNA were performed at sequential time points after infection on aliquots of unstimulated cells from the isolated RO and RA subset preparations. Detected levels of the earliest formed species of HIV DNA were equivalent in RO and RA cells; and RT processing to late species of viral DNA was the same in both phenotypic subsets. Additionally, a high level of viral replication was found in the RO cell subset early after induction with anti-CD3 and was not enhanced selectively by multiple infection cycles. These experiments determined that preferential HIV replication observed in acutely infected RO cells was not due to an inherent difference in cell phenotype susceptibility to infection. Because recent reports have demonstrated that Fusin and CCR5 chemokine receptors serve as secondary receptors in HIV infection for SI and NSI viral phenotypes, respectively (52), we were concerned that our findings might be restricted to infection by SI strains. To address this point, we have repeated our experimental design and included parallel infection with an NSI strain of HIV, JR-CSF (70). Results with the JR-CSF and NL4-3 viral strains were identical, showing consistent preferential HIV replication in the RO phenotype subset.

In studies using RO and RA cells isolated from HIV-infected subjects, preferential replication of virus in the RO subset has also been dependent on the specific stimulus used for induction. Stimulation by PHA mitogen or allogeneic cells has produced equal induction of HIV replication in RO and RA cells from patients $(30,35,36)$; but, stimulation through CD3 crosslinking has resulted generally in preferential induction from the RO subset $(35,57)$. It is difficult to extrapolate directly from findings with in vivo infected cells to an in vitro model, because it is thought that a large portion of HIV DNA found in peripheral blood lymphocytes represents defective, nonviable virus (71). Increased levels of HIV DNA that have been found in RO cells from patients may not reflect an increased susceptibility of this phenotypic subset to infection. Rather, it may represent greater spread of HIV within the RO cell subpopulation due to increased exposure to high virus concentrations, encountered during clonal expansion of infected-cell members. Alternatively, increased HIV load within the RO cell subset may reflect the outcome of reciprocal loss of viral DNA from infected RA cell subpopulations that lack appropriate stimuli or that respond to nonantigenic or cytokine stimuli (60). However, in a series of preliminary experiments, we have found that HIV DNA is not lost from in vitro infected RA cells during long-term culture. 
Many studies have examined whether memory or naive CD4 cells are affected differentially during the course of HIV disease. Most investigations have failed to find a preferential, quantitative loss in either phenotypically defined subset (2831). A recent report (72), looking at coexpression of CD62L adhesion/homing antigen, has described a selective loss of true naive $\mathrm{CD} 4$ cells $\left(\mathrm{RA}^{+} \mathrm{CD} 62 \mathrm{~L}^{+}\right)$with disease progression. In contrast to a lack of preferential quantitative loss, the functional capacity of memory phenotype, CD4 cells has been found consistently to be compromised in patients with HIV infection $(28,32-35)$. Isolated preparations of RO cells exhibit reduced effector capacities to proliferate and secrete lymphokines in response to specific recall antigens or CD3 cross-linking $(29,32,33,73)$. In addition, the RO subset of CD4 cells has been found to be more susceptible than the RA subset to activation-induced death in culture $(34,35)$. The data from our study, using acute HIV infection in vitro, are not inconsistent with these findings from in vivo studies indicating that CD4, memory cell function is affected more severely by HIV disease. The ability of HIV to replicate more efficiently in RO cells might be expected to increase transmission of virus within a population of antigen-primed cells and to contribute subsequently to increased cell dysfunction and susceptibility to activation-induced death.

The findings from our study are perhaps most relevant to understanding the basic biology of HIV-induced pathogenesis. The ability of HIV to replicate preferentially within CD45RO memory phenotype cells after CD3 stimulation may reflect simply the biologic adaptations that HIV has evolved to propagate itself effectively within an infected primate host. The selective utilization by HIV of cell activation pathways that involve CD3 and CD28 signaling is biologically relevant to the in vivo process of antigen presentation required for CD4 cell clonal expansion. Also, the preference for an RO phenotype cell milieu for viral propagation targets the cell population containing functional memory clones, which constantly undergo chronic cycles of expansion in response to common environmental antigens. Thus, HIV appears to have taken advantage of the very same regulatory pathways that govern normal CD4 lymphocyte proliferation and differentiation.

\section{Acknowledgments}

We thank Linda Terry and Dale Disharoon for expert technical assistance, Judy Nordberg for flow cytometry analyses, and Darica Smith for graphics production.

This work was supported by Department of Veterans Affairs Merit Award (C.A. Spina), National Institutes of Health grants AI 27670, AI 29164, and AI 38858 (D.D. Richman), the Research Center for AIDS and HIV Infection of the San Diego VA Medical Center, and the Center for AIDS Research of the University of California at San Diego (NIH grant AI 36214).

\section{References}

1. Fauci, A.S. 1991. Immunopathogenic mechanisms in human immunodeficiency virus (HIV) infection. Ann. Intern. Med. 114:678-693.

2. Oyaizu, N., T.W. McCloskey, M. Coronesi, N. Chirmule, V.S. Kalyanaraman, and S. Pahwa. 1993. Accelerated apoptosis in peripheral blood mononuclear cells (PBMCs) from human immunodeficiency virus type-1 infected patients and in CD4 cross-linked PBMCs from normal individuals. Blood. 82: 3392-3400.

3. Dalgleish, A.G. 1993. Immunobiological aspects of HIV treatment. Curr. Opin. Immunol. 5:608-614.

4. Mosmann, T.R. 1994. Cytokine patterns during the progression to AIDS.
Science (Wash. DC). 265:193-194.

5. Stevenson, M., T.L. Stanwick, M.P. Dempsey, and C.A. Lamonica. 1990. HIV-1 replication is controlled at the level of T cell activation and proviral integration. EMBO (Eur. Mol. Biol. Organ.) J. 9:1551-1560.

6. Zack, J.A., A. Haislip, P. Krongstad, and I.S.Y. Chen. 1992. Incompletely reverse-transcribed human immunodeficiency virus type 1 genomes in quiescent cells can function as intermediates in the retroviral life cycle. J. Virol. 66: 1717-1725.

7. Bukrinsky, M.I., S. Haggerty, P. Dempsey, N. Sharova, A. Adzhubel, L. Spitz, P. Lewis, D. Goldfarb, M. Emerman, and M. Stevenson. 1993. A nuclear localization signal within HIV-1 matrix protein that governs infection of nondividing cells. Nature (Lond.). 365:666-669.

8. von Schwedler, U., R.S. Kornbluth, and D. Trono. 1994. The nuclear localization signal of the matrix protein of HIV-1 allows the establishment of infection in macrophages and quiescent T lymphocytes. Proc. Natl. Acad. Sci. USA. 91:6992-6996.

9. Feinberg, M.B., R.F. Jarrett, A. Aldavini, R.C. Gallo, and F. Wong-Staal. 1986. HTLV-III expression and production involve complex regulation at the levels of splicing and translation of viral mRNA. Cell. 46:807-817.

10. Kim, S.-Y., R. Byrn, J. Groopman, and D. Baltimore. 1989. Temporal aspects of DNA and RNA synthesis during human immunodeficiency virus infection: evidence for differential gene expression. J. Virol. 63:3708-3713.

11. Pavlakis, G.N., and B.K. Felber. 1990. Regulation of expression of human immunodeficiency virus. New Biol. 2:20-31.

12. Feinberg, M.B., and W.C. Greene. 1992. Molecular insights into human immunodeficiency virus type 1 pathogenesis. Curr. Opin. Immunol. 4:466-474.

13. Cullen, B.R. 1994. The role of Nef in the replication cycle of the human and simian immunodeficiency virus. Virology. 205:1-6.

14. Tong-Starksen, S.E., P.A. Luciw, and B.M. Peterlin. 1989. Signaling through $\mathrm{T}$ lymphocyte surface proteins, TCR/CD3 and CD28, activates the HIV-1 long terminal repeat. J. Immunol. 142:702-707.

15. Schmidt, A., L. Henninghausen, and U. Siebenlist. 1990. Inducible nuclear factor binding to the $\mathrm{kB}$ elements of the human immunodeficiency virus enhancer in $\mathrm{T}$ cells can be blocked by cyclosporin A in a signal-dependent manner. J. Virol. 64:4037-4041.

16. Dasgupta, P., P. Saikmar, C.D. Reddy, and E.P. Reddy. 1990. Myb protein binds to human immunodeficiency virus 1 long terminal repeat (LTR) sequences and transactivates LTR-mediated transcription. Proc. Natl. Acad. Sci. USA. 87:8090-8094.

17. McDougal, J.S., A. Mawle, S.P. Cort, J.K.A. Nicholson, G.D. Cross, J.A. Scheppler-Campbell, D.R. Hicks, and J.M. Sligh. 1985. Cellular tropism of the human retrovirus HTLV-III/LAV. Role of T cell activation and expression of the T4 antigen. J. Immunol. 135:3151-3162.

18. Zagury, D., J. Bernard, R. Leonard, R. Cheynier, M. Feldman, P.S. Satin, and R.C. Gallo. 1986. Long-term cultures of HTLV-III infected T cells: a model of cytopathology of T-cell depletion in AIDS. Science (Wash. DC). 231: $850-853$.

19. Margolick, J.B., S.J. Volkman, T.M. Folks, and A.S. Fauci. 1987. Amplification of HTLV-III/LAV infection by antigen-induced activation of T cells and direct suppression by virus of lymphocyte blastogenic responses. J. Immunol. 138:1719-1723.

20. Smith, S.H., M.H. Brown, D. Rowe, R.E. Callard, and P.C.L. Beverley. 1986. Functional subsets of human helper-inducer cells defined by a new monoclonal antibody, UCHL-1. Immunology. 58:63-70.

21. Clement, L.T., N. Yamashita, and A.M. Martin. 1988. The functionally distinct subpopulations of human $\mathrm{CD}^{+}$helper inducer $\mathrm{T}$ lymphocytes defined by anti-CD 45R antibodies derive sequentially from a differentiation pathway that is regulated by activation-dependent post-thymic differentiation. J. Immunol. 141:1464-1470.

22. Akbar, A.N., L. Terry, A. Timms, P.C.L. Beverley, and G. Janossy. 1988. Loss of CD45R and gain of UCHL1 reactivity is a feature of primed T cells. J. Immunol. 140:2171-2178.

23. Merkenschlager, M., L. Terry, R. Edwards, and P.C.L. Beverley. 1988. Limiting dilution analysis of proliferative responses in human lymphocyte populations defined by the monoclonal anti-body UCHL1: implications for differential CD45 expression in T-cell memory formation. Eur. J. Immunol. 18:1653-1661.

24. Sanders, M.E., M.W. Makgoba, S.O. Sharrow, D. Stephany, T.A. Springer, H.A. Young, and S. Shaw. 1988. Human memory T lymphocytes express increased levels of three cell adhesion molecules (LFA-3, CD2, and LFA-1) and three other molecules (UCHLI, CDw29, and PGP-1) and have enhanced IFN-gamma production. J. Immunol. 140:1401-1407.

25. Ferrer, J.M., A. Plaza, M. Kreisler, and F. Diaz Espada. 1992. Differential interleukin secretion by in vitro activated human CD45R and CD45RO $\mathrm{CD}^{+}{ }^{+} \mathrm{T}$ cell subsets. Cell. Immunol. 141:10-20.

26. Michie, C.A., A. McLean, C. Alcock, and P.C.L. Beverley. 1992. Lifespan of human lymphocyte subsets defined by CD45R isoforms. Nature (Lond.). 360:264-265.

27. Tough, D.F., and J. Sprent. 1994. Turnover of naive- and memory-phenotype T cells. J. Exp. Med. 179:1127-1135.

28. Miedema, F. 1992. Immunological abnormalities in the natural history of HIV infection: mechanisms and clinical relevance. Immunodeficiency Rev. 3: 173-193. 
29. Chou, C., V. Gudeman, S. O'Rourke, V. Isacescu, R. Detels, G.J. Williams, R.T. Mitsuyasu, and J.V. Giorgi. 1994. Phenotypically defined memory $\mathrm{CD}^{+}{ }^{+}$cells are not selectively decreased in chronic HIV disease. J. Acquired Immune Defic. Syndr. 7:665-675.

30. Meyaard, L., S.A. Otto, B. Hooibrink, and F. Miedema. 1994. Quantitative analysis of $\mathrm{CD}^{+} \mathrm{T}$ cell function in the course of human immunodeficiency virus infection. Gradual decline of both naive and memory alloreactive T cells. J. Clin. Invest. 94:1947-1952.

31. Bruunsgaard, H., C. Pedersen, E. Scheibel, and B.K. Pedersen. 1995. Increase in percentage of $\mathrm{CD} 45 \mathrm{RO}^{+} / \mathrm{CD}^{+}$cells is associated with previous severe primary HIV infection. J. Acquired Immune Defic. Syndr. Hum. Retrovirol. 10:107-114.

32. Schellekens, P.T., M.T. Roos, F. De Wolf, J.M. Lange, and F. Miedema. 1990. Low T-cell responsiveness to activation via CD3/TCR is a prognostic marker for AIDS in HIV-infected men. J. Clin. Immunol. 10:121-127.

33. Cayota, A., F. Vuillier, D. Scott-Algara, V. Feuillie, and G. Dighiero. 1992. Impaired proliferative capacity and abnormal cytokine profile of naive and memory CD4 T cells from HIV-seropositive patients. Clin. Exp. Immunol. $88: 478-483$.

34. Janossy, G., N. Borthwick, R. Lomnitzer, E. Medina, S.B. Squire, A.N. Phillips, M. Lipman, M.A. Johnson, C. Lee, and M. Bofill. 1993. Lymphocyte activation in HIV-1 infection. I. Predominant proliferative defects among $\mathrm{CD}^{2} \mathrm{RO}^{+}$cells of the CD4 and CD8 lineages. AIDS (Phila.). 7:613-624.

35. Medina, E., N. Borthwick, M.A. Johnson, S. Miller, and M. Bofill. 1994. Flow cytometric analysis of the stimulatory response of $\mathrm{T}$ cell subsets from normal and HIV $-1^{+}$individuals to various mitogenic stimuli in vitro. Clin. Exp. Immunol. 97:266-272.

36. Schnittman, S.M., H.C. Lane, J. Greenhouse, J.S. Justement, M. Baseler, and A. Fauci. 1990. Preferential infection of $\mathrm{CD}^{+}$memory T cells by human immunodeficiency virus type 1: evidence for a role in the selective T-cell functional defects observed in infected individuals. Immunology. 87:6058-6062.

37. Spina, C.A., T.J. Kwoh, M.Y. Chowers, J.C. Guatelli, and D.D. Richman. 1994. The importance of nef in the induction of human immunodeficiency virus type 1 replication from primary quiescent CD4 lymphocytes. J. Exp. Med. 179:115-123.

38. Adachi, A., H.E. Gendelman, S. Koenig, T. Folks, R. Willey, A. Rabson, and M.A. Martin. 1986. Production of acquired immunodeficiency syndrome-associated retrovirus in human and non-human cells transfected with an infectious molecular clone. J. Virol. 59:284-291.

39. Folks, T.M., S. Benn, A. Rabson, T. Theodore, M.D. Hoggan, M. Martin, M. Lightfoote, and K. Sell. 1985. Characterization of a continuous T-cell line susceptible to the cytopathic effects of the AIDS retrovirus. Proc. Natl. Acad. Sci. USA. 82:4539-4543.

40. Felgner, P.L., T.R. Gader, M. Holm, R. Roman, H.W. Chan, M. Wenz, J.P. Northrop, G.M. Ringold, and M. Danielson. 1987. Lipofectin: a highly efficient, lipid-mediated DNA-transfection procedure. Proc. Natl. Acad. Sci. USA. 84:7413-7417.

41. Haertle, T., C.J. Carrera, J.S. McDougal, L.C. Sowers, D.D. Richman, and D.A. Carson. 1988. Metabolism and anti-HIV activity of $2^{\prime}$-halo-2', $3^{\prime}$ dideoxyadenosine derivatives. J. Biol. Chem. 263:5870-5875.

42. Spina, C.A., J.C. Guatelli, and D.D. Richman. 1995. Establishment of a stable, inducible form of human immunodeficiency virus type 1 DNA in quiescent CD4 lymphocytes in vitro. J. Virol. 69:2977-2988.

43. Baroja, M.L., K. Lorre, F. Van Vaeck, and J.L. Ceuppens. 1989. The anti-T cell monoclonal antibody 9.3 (anti-CD28) provides a helper signal and by-passes the need for accessory cells in T cell activation with immobilized antiCD3 and mitogen. Cell. Immunol. 120:205-217.

44. Guatelli, J.C., T.R. Gingeras, and D.D. Richman. 1990. Alternative splice acceptor utilization during HIV-1 infection of cultured cells. J. Virol. 64: 4093-4098.

45. Maniatis, T., E.F. Fritsch, and J. Sambrook. 1989. Molecular Cloning: A Laboratory Manual. Cold Spring Harbor Laboratory Press, Cold Spring Harbor, NY. p. 5.

46. Zack, J.A., S.J. Arrigo, S.R. Weitsman, A.S. Go, A. Haislip, and I.S.Y. Chen. 1990. HIV-1 entry into quiescent primary lymphocytes: molecular analysis reveals a labile, latent viral structure. Cell. 61:213-222.

47. Davis, G.R., K. Blumeyer, L. DiMichele, K. Whitfield, H. Chappelle, N. Riggs, S. Gosh, P. Kao, E. Fahey, J. Guatelli, et al. 1990. Detection of HIV-1 in AIDS patients using amplification-mediated hybridization analysis: reproducibility and quantitative limitations. J. Infect. Dis. 162:13-20.

48. Liu, Y., and P.S. Linsley. 1992. Costimulation of T-cell growth. Curr. Opin. Immunol. 4:265-270.

49. Jenkins, M.K., P.S. Taylor, S.D. Norton, and K.B. Urdhl. 1991. CD28 delivers a costimulatory signal involved in antigen-specific IL-2 production by human T cells. J. Immunol. 147:2461-2466.

50. Schwartz, R.H. 1992. Costimulation of T lymphocytes: the role of CD28, CTLA-4, and B7/BB1 in interleukin-2 production and immunotherapy. Cell. 71: 1065-1068.

51. Levine, B.L., J.D. Mosca, J.L. Riley, R.G. Carroll, M.T. Vahey, L.L. Ja- godzinski, K.F. Wagner, D.L. Mayers, D.S. Burke, O.S. Weislow, et al. 1996. Antiviral effect and ex vivo CD4+ T cell proliferation in HIV-positive patients as a result of CD28 costimulation. Science (Wash. DC). 272:1939-1943.

52. Dragic, T., V. Litwin, G.P. Allaway, S.R. Martin, Y. Huang, K.A. Nagashima, C. Cayanan, P.J. Maddon, R.A. Koup, J.P. Moore, and W.A. Paxton 1996. HIV-1 entry into CD4+ cells is mediated by the chemokine receptor C-C CKR-5. Nature (Lond.). 381:667-673.

53. Hazan, U., D. Thomas, J. Alcami, F. Bachelerie, N. Israel, H. Yssel, J.L. Virelizier, and F. Arenzana-Seisdedos. 1990. Stimulation of a human T-cell clone with anti-CD3 or tumor necrosis factor induces NF-kB translocation but not human immunodeficiency virus 1 enhancer-dependent transcription. Proc. Natl. Acad. Sci. USA. 87:7861-7865.

54. Moran, P.A., M.L. Diegel, J.C. Sias, J.A. Ledbetter, and J.M. Zarling. 1993. Regulation of HIV production by blood mononuclear cells from HIV infected donors: lack of correlation between HIV-1 production and T cell activation. J. Acquired Immune Defic. Syndr. Hum. Retrovirol. 9:455-464.

55. Asjo, B., D. Cefai, P. Debre, Y. Dudoit, and B. Autran. 1993. A novel mode of human immunodeficiency virus type 1 (HIV-1) activation: ligation of CD28 alone induces HIV-1 replication in naturally infected lymphocytes. $J$. $\mathrm{Vi}$ rol. $67: 4395-4398$

56. Helbert, M.R., J. L'age-Stehr, and N.A. Mitchison. 1993. Antigen presentation, loss of immunological memory and AIDS. Immunol. Today. 14:340 344.

57. Cayota, A., F. Vuillier, D. Scott-Algara, V. Feuillie, and G. Dighiero. 1993. Differential requirements for HIV-1 replication in naive and memory CD4 T cells from asymptomatic HIV-1 seropositive carriers and AIDS patients. Clin. Exp. Immunol. 91:241-248.

58. Rothstein, D.M., A. Da Silva, K. Sugita, M. Yamamoto, K.V. Prasad, C. Morimoto, S.F. Schlossman, and C.E. Rudd. 1993. Human CD4/CD45RA ${ }^{+}$and CD4/CD45RA ${ }^{-}$T cell subsets express CD4-p56lck complexes, CD4-associated lipid kinases, TCR/CD3-p59fyn complexes, and share similar tyrosine kinase substrates. Int. Immunol. 4:409-418.

59. Janeway, C.A., and K. Bottomly. 1994. Signals and signs for lymphocyte responses. Cell. 76:275-285.

60. Woods, T.C., S.T. Butera, and T.M. Folks. 1997. HIV preferentially infects CD4, CD45RO lymphocyte populations in vitro. Blood. 89:1635-1642.

61. Baur, A.S., E.T. Sawai, P. Dazin, W.J. Fantl, C. Cheng-Mayer, and B.M. Peterlin. 1994. HIV-1 Nef leads to inhibition or activation of T cells depending on its intracellular location. Immunity. 1:373-384.

62. Sawai, E.T., A. Baur, H. Struble, B.M. Peterlin, J.A. Levy, and C. ChenMayer. 1994. HIV-1 Nef associates with a cellular serine kinase in T lymphocytes. Proc. Natl. Acad. Sci. USA. 91:1539-1543.

63. Bodéus, M., A. Marie-Cardine, C. Bougeret, F. Ramos-Morales, and R. Benarous. 1995. In vitro binding and phosphorylation of human immunodeficiency virus type 1 Nef protein by serine/threonine protein kinase.J. Gen. Virol. 76:1337-1344.

64. Collette, Y., H. Dutartre, A. Benziane, F. Ramos-Morales, R. Benarous, M. Harris, and D. Olive. 1996. Physical and functional interaction of nef with lck. J. Biol. Chem. 271:6333-6341.

65. Guy, B., M.P. Kieny, Y. Riviere, C. LePeuch, K. Dott, M. Girard, L. Montagnier, and J.P. Lecocq. 1987. HIV F/3' orf encodes a phosphorylated GTP-binding protein resembling an oncogene product. Nature (Lond.). 330: 266-269.

66. Garcia, J.V., and A.D. Miller. 1991. Serine phosphorylation-independent downregulation of cell-surface CD4 by nef. Nature (Lond.). 350:508-511.

67. Luria, S., I. Chambers, and P. Berg. 1991. Expression of the type 1 human immunodeficiency virus nef protein in $\mathrm{T}$ cells prevents antigen receptormediated induction of interleukin-2 mRNA. Proc. Natl. Acad. Sci. USA. 88: $5326-5330$.

68. Niederman, T.M.J., J.V. Garcia, W.R. Hastings, S. Luria, and L. Ratner. 1992. Human immunodeficiency virus type 1 nef protein inhibits NF-kB induction in human T cells. J. Virol. 66:6213-6219.

69. Niederman, T.M.J., W.R. Hastings, S. Luria, J.C. Bandres, and L. Ratner. 1993. HIV-1 nef protein inhibits the recruitment of AP-1 DNA-binding activity in human T-cells. Virology. 194:338-344.

70. Koyanagi, Y., S. Miles, R.T. Mitsuyasu, J.E. Merrill, H.V. Vinters, and I.S.Y. Chen. 1987. Dual infection of the central nervous system by AIDS viruses with distinct cellular tropisms. Science (Wash. DC). 236:819-882.

71. Seshamma, T., O. Bagasra, D. Trono, D. Baltimore, and R.J. Pomerantz. 1992. Blocked early-stage latency in the peripheral blood cells of certain individuals infected with human immunodeficiency virus type 1. Proc. Natl. Acad. Sci. USA. 89:10663-10667.

72. Roederer, M., J.G. Dubs, M.T. Anderson, P.A. Raju, and L.A. Herzenberg. 1995. CD8 naive T cell counts decease progressively in HIV-infected adults. J. Clin. Invest. 95:2061-2066.

73. Tassinari, P., L. Deibis, I. Blanca, N.E. Bianco, and E.G. de Perez. 1995. Decreased T-cell proliferative response to common environmental antigens could be an indicator of early human immunodeficiency virus-mediated lymphocyte lesions. Clin. Diagn. Lab. Immunol. 2:404-407. 